\title{
An Assessment of Hazards and Occupational Health \& Safety Practices for Workers in the Textile Industry: A Case Study
}

\author{
Mohsin Ali Shaikh, Song Weiguo, Muhammad Usman Shahid, Hameeda \\ Ayaz, Maryam Ali
}

To Link this Article: http://dx.doi.org/10.6007/IJARBSS/v8-i12/5016

DOI: 10.6007/IJARBSS/v8-i12/5016

Received: 03 Nov 2018, Revised: 27 Nov 2018, Accepted: 15 Dec 2018

Published Online: 22 Dec 2018

In-Text Citation: (Shaikh, Weiguo, Shahid, Ayaz, \& Ali, 2018)

To Cite this Article: Shaikh, M. A., Weiguo, S., Shahid, M. U., Ayaz, H., \& Ali, M. (2018). An Assessment of Hazards and Occupational Health \& Safety Practices for Workers in the Textile Industry: A Case Study. International Journal of Academic Research in Business and Social Sciences, 8(12), 333-347.

Copyright: (C) 2018 The Author(s)

Published by Human Resource Management Academic Research Society (www.hrmars.com)

This article is published under the Creative Commons Attribution (CC BY 4.0) license. Anyone may reproduce, distribute, translate and create derivative works of this article (for both commercial and non-commercial purposes), subject to full attribution to the original publication and authors. The full terms of this license may be seen

at: http://creativecommons.org/licences/by/4.0/legalcode

Vol. 8, No. 12, 2018, Pg. 333 - 347

Full Terms \& Conditions of access and use can be found at http://hrmars.com/index.php/pages/detail/publication-ethics 


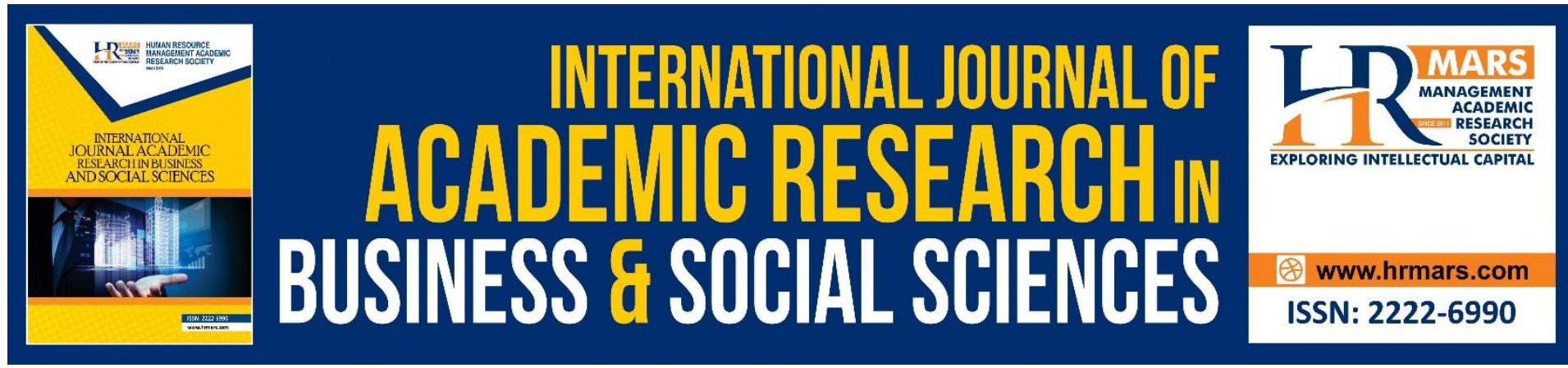

\title{
An Assessment of Hazards and Occupational Health \& Safety Practices for Workers in the Textile Industry: A Case Study
}

\author{
Mohsin Ali Shaikh ${ }^{1}$, Song Weiguo, ${ }^{2}$ Muhammad Usman \\ Shahid ${ }^{3}$, Hameeda Ayaz ${ }^{4}$, Maryam Ali ${ }^{5}$ \\ 1, 2, 3 State Key Laboratory of Fire Science, University of Science and Technology of China, \\ Hefei -230026- Anhui, China \\ ${ }^{4}$ Department of Chemistry, Quaid-e-Azam University, Islamabad, Pakistan, \\ ${ }^{5}$ School of Economics and Management, Yanshan University Qinhuangdao-066004-Hebei, \\ P.R.China
}

\section{ABSTRACT}

Thousands of workers have been killed and injured due to unsafe buildings, worst emergency system and poor occupational health and safety practices in textile industries. It is very essential to recognize the hazards in the workplace. This study was carried out in the textile industry at Kotri, Sindh, Pakistan with the objective to assess hazards and safety practices for workers. The data was collected through the questionnaire of Musa et al (2012) with few modifications. The SPSS software was used to analyze the data and obtain appropriate results. Respondents agreed with the great extent that there was an existence of hazards like; Noise, Fire smoke, Smoking, Fatigue, Drinking alcohol, Job stress and Cotton dust particles at the great extent and these hazards affect directly or indirectly on the health of workers. Occupational Health and Safety Practices (OHSP) include; Awareness of clinic, Awareness of hazards, Awareness of preventive measures, inaccurate instrument make trouble, medical bill facility, and periodic medical test was being carried out in their organizations while; personal protective equipment's, pre-employment medical examination, training on hazard prevention were not available in the textile industry. Moreover, the majority of the respondents agreed that personal protective devices were not available in the company. This indicates that occupational health and safety practices were not satisfied at the workplace. Therefore, the organization should take the serious implementation of (OHSP) at the workplace

Keywords: Assessment, Hazards and safety practices, Workers, Textile, Industry.

\section{Introduction}

There are various disciplines which are related to Occupational Health and Safety like epidemiology, industrial hygiene, occupational nursing, toxicology, engineering and occupational nursing. It involves the conditions and surroundings that influence workers and other related human beings at working environment. Occupational health and safety 
practices is the large concern for the protection from hazards at the workplace. According to the International labor organization (ILO) and World Health Organization (WHO), occupational health is described as "Occupational health should be a goal at the maintenance and promotion of the topmost quality of mental, physical and social well-being of employees in all kinds of work". Occupational health and safety (OHS) is a multidisciplinary field include; the disciplines of occupational medicine, occupational nursing, industrial hygiene, epidemiology, toxicology, engineering (Bakri, Zin, Minson, \& Muhammad, 2006). Occupational Health and Safety practices help to enhance the productivity as well as decrease the workplace accidents through progressive guidance over the performance of workers (Vinodkumar, 2005). International Labor Organization (ILO) has stated that an occupational accident affects the lives of human being. Approximately, 317 million accidents have taken place with human being per year.

In 2014, thousands of peoples have died due to heat waves in Karachi. The governments of Sindh were not serious against heat waves issue and only fixed minimum $1 \%$ of the total budget for Sindh environment. This insufficient budget is unable to stabilize the environment for the human being in Sindh (Sheharyar, 2016). The occupational hazards have developed enormously low mishap rates, occupational diseases, and harmful effects on the textile industries. Textile industries possessed different types of hazards e.g. physical, biological, chemical and ergonomic hazards. These hazards lead to an unhealthy environment, number of accidents and dangerous diseases in the workplace (Malik, 2010). The textile industries workers are suffering from several diseases i-e lungs cancer, Tb, kidney stones and ENT (ear, nose and throat) (Rana, 2005). Industries of Pakistan require uncompromising development in terms of occupational health and safety practices implementation because; they did not give as much consideration as they need to this valuable parameter (Farooqui, Ahmed, \& Panthi, 2007) (Waqas, Talha, \& Tabassum, 2014). A work-related death in Pakistan is much higher than any progressive countries (Hassan, 2012).

The occupational injuries have the great impact on the lives of workers. The sleeping disturbance, fatigue, lack of training and job stress increase the injuries at the occupational place. These factors expand the risk of occupational injury. The solution to these problems is to promote the basic health and safety technique to every worker. Health education among younger, male and female workers minimizes the stress and sleep disorder (Jaiswal, 2012) (Aderaw, Dagnew, \& Tadesse, 2011). Physical health fitness, skill development, and psychosocial happiness are related to workability. Relevant work environment enhances the achievement of the employers at the workplace (IIImarinen, 1997). The risk injury factors have been mostly seen in labor work occupation. Such important factors like two different jobs in a day, late shift, performing duty full time and having over time are the main causes of an occupational injury. Another factor related to occupational health is very complicated. The race/ethnicity has a great impact on the occupational hazards. Most workers are obstinate and deviate themselves owing worst impact on the occupation (Larkin, Strong, Frederick, \& Zimmerman, 2005). Korea and the USA get the same type of hazards finishing, mining, forestry, construction, agriculture and textile sectors follow the same risk in both countries. The United States of America is more anxious about health and safety, but Korea also gives more prevalence to save their industries from occupational risk. However, the Surveillance system and safety initiative decision is required to prevent occupational risk and injury at Korea (Ahn, Bena, \& Bailer, 2004). The continuously sound of machines create noise pollution which is harmful to the brain. Noise has direct influence on brain diseases. The government should see the circumstances of safety and provide the fund for research purpose in the 
interest to prevent hazards at working place (Gupta, Nag, Datta, Roy, Das, \& Yasir, 2015). The workers are facing a problem like musculoskeletal, respiratory disease and eye irritation because of hazard in working place. It is essential to realize the risk in an environment that health and safety may be compulsory to reduce the hazard from the workplace (Hiremath, Kuttumuri, Kumar, \& Hiremath, 2014). Those workers are in the hemp and jute manufacturing department. It is $100 \%$ sure that organic dust enhances the respiratory problem like Byssinosis. These diseases decrease the quality of life. The occupational health standard institutes are taking serious action against Byssinosis disease Mukremin, Emri, Demir, Thorne, Karakoca, Bilir, \& Baris, 2016). The ergonomic factors affect the efficiency of an organization. Ergonomics factors directly affect the workers' health and make problems to achieve the target value etc. High profit can be achieved through employee's satisfaction. The satisfied worker will effort more for the organization and provides a better result in future (Narayanan, Mathew, \& Vinodyeldo, 2013). The main objectives of the business organization to achieve the maximum profit. This achievement may be accomplished by providing the safety of workers in the organization safety of employees upgrade the productivity. Hazards occurs a severe negative impact on productivity. It is necessary to minimize the hazards from working place. Workers training on hazards prevention can positively influence productivity rate. The organization needs to arrange secure and useful environment for the achievement of the job. Educational program service is essential to minimize the occupational hazards and improve productivity (Ofoegbu, Olawepo, \& Ibojo, 2013).

\section{Methodology}

Data were collected from respondents in different departments. Use of a questionnaire of (Musa, \& Bamidele, 2012) with little modifications and inclusive literature review was managed in order to achieve goals and objectives. In this research, the data was analyzed through SPSS software (Statistical Package for the Social Sciences) 20. SPSS is the flexible package that helps to analyze several types of data. The quantitative approach involves questionnaire which contains close ended and open questions of five-point Likert scale type. For this purpose, 600 questionnaires were given to the workers of the textile mill and out of that 488 were usable for this study. After accumulating the questionnaires, data were analyzed through SPSS software (Statistical Package for Social Sciences 20) and percentage, mean, standard deviation and variance were computed.

\section{Results and Discussion}

Data was collected from the textile mill Kotri, Sindh, Pakistan through the questionnaire which was taken from (Musa, \& Bamidele, 2012) \& edited it. The questionnaire consisted of 39 questions in different sections. The textile mill consists of two units ( $1 \& 2$ ). Data was collected from unit no. 1, where approximately 600 workers were working. The best practices for research are to receive the information, awareness and knowledge through the survey at the industrial workplace (Draugalis, Coons, \& Plaza, 2000).

\section{Rate of response}

600 questionnaires were distributed among the workers, and they were provided instruction in their own language that how to fill questionnaires. Out of 600 questionnaires, $112(18.66 \%)$ questionnaires were discarded because $91(15.16 \%)$ respondents were partially filled and 21 (3.5\%) workers straightforward denied filling the questionnaires. Therefore; 488 questionnaires i.e. $81.33 \%$ was used for this research work as shown in Fig. 1. 


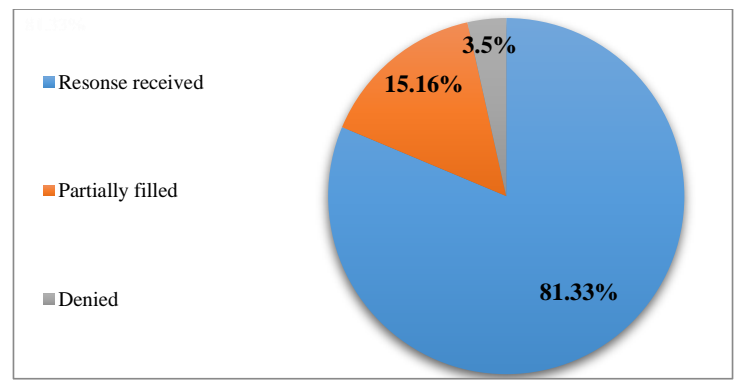

Fig. 1. Response rate of workers

\section{Hazards at Workplace}

Respondents were provided 5 point Likert scale as 1 to 5 , where $1=$ not sure, $2=$ not at all, 3 = some extent, $4=$ great extent and 5 = very great extent. Collected data were statistically analyzed in terms of mean, standard deviation and variance which are summarized in Table. 1.

\section{Table 1}

Hazards at workplace

\begin{tabular}{|l|c|c|}
\hline Variable & Mean & S.D \\
\hline Noise & 4.55 & 1.00 \\
\hline Fire smoke & 4.51 & 0.89 \\
\hline Tobacco Smoking & 3.81 & 0.57 \\
\hline Fatigue & 3.79 & 1.45 \\
\hline Drinking alcohol & 3.76 & 0.68 \\
\hline Job stress & 3.72 & 1.55 \\
\hline Cotton dust particles & 3.64 & 1.62 \\
\hline Mainpuri & 3.52 & 0.92 \\
\hline Sleeping disturbance & 3.38 & 0.98 \\
\hline Improper furniture & 3.35 & 1.02 \\
\hline Vibration & 3.28 & 1.10 \\
\hline Gutka & 3.27 & 1.13 \\
\hline Temperature & 3.20 & 0.95 \\
\hline Naswar & 3.09 & 1.07 \\
\hline Machines injury & 2.99 & 1.08 \\
\hline Dark and poor light & 2.87 & 1.15 \\
\hline Lubricant burn smell & 2.80 & 1.19 \\
\hline Manual lifting object & 2.45 & 0.97 \\
\hline Electricity shock & 1.60 & 0.87 \\
\hline Accident fall & 1.58 & 0.70 \\
\hline
\end{tabular}

Table. 1 indicates that Mean value of this factor was computed as 4.55 with S.D of 1.00. Mean value of this variable is near to 5 . This reflects that respondents of this study perceived this factor as a very great extent hazard. In this regard observations of respondents were verified by Sound meter. The noise level was recorded in blow room $84 \mathrm{~dB}$, card $88 \mathrm{~dB}$, simplex $91 \mathrm{~dB}$, ring $95 \mathrm{~dB}$ and autocone $82 \mathrm{Db}$ (decibel). According to (OSHA standard 2201-08R 2015)75 dB noise level is non-hazardous whereas; hearing protection regulations start from $85 \mathrm{~dB}$ and 95 
$\mathrm{dB}$ noise levels are the risk of hearing damage. The maximum noise in manufacturing organizations should be 75-80dB (Hassan, 2012).

Table. 1 indicates that Mean value of this factor was computed as 4.51 with S.D of 0.89 and Variance of 0.79 . This reflects that respondents of this study perceived this factor as a very great extent hazard. According to (OSHA Standards-29 CFR) industries should prepare workers about the injurious effect of fire smoke hazards at the workplace and provide them the education of fire smoke that what to do in a fire emergency. The industrial accidents are especially occurring due to fire in developing countries. Chittagong is the port city of Bangladesh, where 100 people injured and 54 workers were burnt by fire in a textile factory. The fire caught most of the whole building within seconds (Skeers, 2006).

Table. 1 indicates that Mean value of this factor was computed as 3.81 with S.D of 0.57. This reflects that respondents of this study perceived this factor as a great extent hazard for themselves and creating the problem in terms of decreased productivity, absenteeism, medical expenditure and etc. The non-smokers increase the productivity as compared to the smokers who decreases the productivity. Mostly Smokers remain absent from work due to diseases like stress, respiratory and lung problems (Halpern, Shikiar, Rentz, \& Zeba, 2011). Table. 1 indicates that Mean value of this factor was computed as 3.79 with S.D of 1.45. Mean value of this variable is near to 4 . This reflects that respondents of this study perceived this factor as a great extent hazard. The fatigue is a state in which a person is exhausted, tired and less energetic (Procopio, Cruz, Scavonec, Giunta, Pestana, Roza, 2014). The fatigue is also found to be related to muscular-skeletal and mental problems (Breslow, 1992). Table. 1 indicates that Mean value for drinking alcohol was calculated as 3.76 with S.D of 0.68. Mean value of this variable is near to 4 . This reflects that respondents of this study perceived this factor as great extent hazard. The alcohol has a great adverse impact on the human body. Alcohol provides the result in negative including; injury, sadness and fatality. Alcohol reduces the worker efficiency, productivity, assault and disturbance opposing other and misbehaves with family members (Gmel, \& Rehm, 2003). Table. 1 indicates that Mean value for job stress was calculated as 3.72 with S.D of 1.55. Mean value of this variable is near to 4 . This reflects that respondents of this study perceived this factor as a great extent hazard. The job stress is a psychological hazard. This stress follows as the most omnipresent and prominent health hazard in the social environment. Stressful job makes the worker mentally disturbed (Li, Chen, Wu \& Sung, 2011).

Table. 1 indicates that Mean value of this factor was calculated as 3.64 with S.D of 1.62. Mean value of this variable is near to 4 . This reveals that respondents of this study perceived this factor as a great extent hazard. The vertical elutriator instrument was not available that's why the observations of respondents were not checked through the vertical elutriator instrument. According to (OSHA Standard 29 CFR 1910.1043) the normal range of cotton dust particles should not be above 200 micrograms per cubic meter at the workplace. The cotton dust possesses small microscopic particles which are present in our atmosphere. Workers inhale dust particles into the body which causes major diseases like Byssinosis and chest problems (Kane, 2001). The inadequate ventilation at workplace promotes the cotton dust in the atmosphere (Haider, Taous, Rahim, Zahurul Huq, \& Abdullah, 2008). Table. 1 indicates that Mean value for mainpuri was computed as 3.52 with S.D of 0.92 . Mean value of this variable is near to 4 . This reflects that respondents of this study perceived this factor as a great extent hazard. The negative impacts of mainpuri. Mainpuri caused sub mucous fibrosis in youngsters and it contains major impurities like Pilocarpine, Alkaloids, 
Muscaringarecoline increased the risk of cardiovascular problems which are very harmful to health (Newspapers staff reported, 2011, December 29).

Less sleep workers are unable to perform their work in the working environment. According to the report of U.S. Centers for Disease Control and Prevention that approximately 50 to 70 million American adults hurt from wakefulness and sleep disorders. Table. 1 indicates that Mean value of this factor was calculated as 3.38 with S.D of 0.98 . Mean value of this variable is near to 3 . This exposes that respondents of this study observed this factor as some extent hazard. The sleep disturbance has a great influence on the worker's life. Workers can't perform well in the workplace due to lack of sleep (Serkalem, Haimanot, \& Ansha, 2014).

Improper furniture/ equipment leads to enormous side effects. It has a great influence physically and mentally and affects the performance of workers. Table. 1 indicates that Mean value of this factor was calculated as 3.35 with S.D of 1.02. Mean value of this variable is near to 3. This exposes that respondents of this study observed this factor as some extent hazard. The improper furniture/ equipment decreases workers' performance and productivity. Proper furniture helps to motivate the workers and enhancing their performance substantially (Amina, \& Shehla, 2009).

Vibration creates the injury problems for workers. It develops enormous diseases like ergonomic-injuries, affecting feeling, grip, and dexterity. Table. 1 indicates that Mean value of this factor was calculated as 3.28 with S.D of 1.10. Mean value of this variable near to 3 . This means that respondents of this study perceived this factor as some extent hazard. The observations of respondents were measured through vibration meter. The vibration were recorded in blow room $7.4 \mathrm{~mm} / \mathrm{s}$, card $7.01 \mathrm{~mm} / \mathrm{s}$, simplex $9.09 \mathrm{~mm} / \mathrm{s}$, ring $11.2 \mathrm{~mm} / \mathrm{s}$ and Autocone $9.67 \mathrm{~mm} / \mathrm{s}$. According to the (VIBRATION SEVERITY PER ISO 10816) vibration at Good $=0.71 \mathrm{~mm} / \mathrm{s}$, Satisfactory $=2.80 \mathrm{~mm} / \mathrm{s}$, unsatisfactory $=7.10 \mathrm{~mm} / \mathrm{s}$ and unacceptable $=$ $28.00 \mathrm{~mm} / \mathrm{s}$. National Hazard Exposure Worker Surveillance (2008) has reported that vibration has a serious consequence for workers. The high-level vibration exposed approximately $24 \%$ of Australian workers at the workplace.

The most harmful materials which are used in gutka are Areca nut, Catechu, paraffin, tobacco, paraffin wax, savory flavorings and slaked lime. The people consume their energy in chewing and sucking gutka. It develops the throat, mouth cancer and heart diseases. Table. 1 indicates that Mean value for gutka was calculated as 3.27 with S.D of 1.13. Mean value of this variable is near to 3 . This reflects that respondents of this study perceived this factor as some extent hazard. The majority of the physicians have declared the drawbacks of gutka. Gutka damages the efficiency power of man, woman, adults and children. The senior ENT surgeon Pakistan Medical Association Dr. Qaiser Sajjad suggested that gutka, betelnuts and mainpuri caused fungal infection, cancer of gums, throat, prostate and esophagus, liver and stomach.

Table. 1 indicates that Mean value of temperature factor was calculated as 3.20 with S.D of 0.95. Mean value of this variable is near to 3 . This reflects that respondents of this study perceived this factor as some extent hazard. In this regard observations of respondents were verified by the thermometer. The temperature was recorded in Blowroom $29^{\circ} \mathrm{C}$, the card at $27^{\circ} \mathrm{C}$, simplex $31^{\circ} \mathrm{C}$, ring $39^{\circ} \mathrm{Cand}$ Autocone $30^{\circ} \mathrm{C}$ (Celsius). According to (OSHA DTSEM FS-3743 $08 / 2014$ ) standard has recommended that temperature should not greater than $38^{\circ} \mathrm{C}$ at the workplace. The symptoms and signs of temperature are the weakness, headache, heavy sweating, confusion and dizziness. 
The high and low temperature is the cause of many problems for workers. Temperature affects the workers' productivity and changes the condition of the environment (Seppanen, William, \& Lie, 2006).

Table. 1 indicates that Mean value for Naswar was calculated as 3.09 with S.D of 1.07. Mean value of this variable is near to 3 . This reflects that respondents of this study perceived this factor as some extent hazard. (The Express Tribune, 2010) have mentioned in their news report that Naswar is more dangerous to health than smoking. In the same report, Prof Dr. Mukhtar Zaman said that Naswar has a great influence on health and affects the stomach, mouth cancer, lung problems, and bronchitis, heart and kidney diseases (Farhan, 2010).

An accident which occurs by the machine during the manufacturing process is called machine injury. There are thousands of workers working in making fabric and yarn for clothing in a textile mill and spend most of their time near the machines and on the production floor. Table. 1 indicates that Mean value was calculated as 2.99 with S.D of 1.08. Mean value of this variable is near to 3 . This reveals that respondents of this study observed this factor as some extent hazard.

The workers lose their body parts like; fingers, hand, face, mouth and foot due to machine injuries. Hollow needle injects into the body during work, resulting in human immunodeficiency Virus (HIV), hepatitis C and infectious disease in the body (Ind, \& Jeffries, 1999).

Table. 1 indicates that Mean value for dark and poor light was calculated as 2.87 with S.D of 1.15. Mean value of this variable is near to 3 . This reveals that respondents of this study observed this factor as some extent hazard. In the textile mill, it was observed that many tubes of light were unable to light in the workplace. Poor lighting impacts the health of workers at work and also causing the diseases like; headaches, eyestrain and migraine. The health and safety of textile workers can be improved by checking standards of light with OSHA and changing old lights with new lights. Dark light may be harmful to the eyes, while poor light can destroy the quality of work and reduce the overall productivity.

The observations of respondents were checked by Lux meter in Foot-candle (Fc). The light level were recorded in Blowroom $13(\mathrm{Fc})$, card $24(\mathrm{Fc})$, simplex $19(\mathrm{Fc})$, ring $16(\mathrm{Fc})$ Autocone 27 (Fc). According to the (OSHA Standard 1926.56), the accepted maximum lighting requirements for industry must be 30 foot-candles $(\mathrm{Fc})$. The proper lighting is very important for the textile sector. The proper lighting systems can easily protect the workers from eye diseases.

Table. 1 indicates that Mean value for lubricant burn smell was calculated as 2.80 with $S D=1.19$. Mean value of this variable is near to 3 . This reveals that respondents of this study observed this factor as some extent hazard. According to (OSHA - HA-3590-2012 DSG $01 / 2013$ ) the strategy for reducing workers in exposure to lubricant burn smell includes; the emissions can be minimized by the preventive maintenance of diesel engines. There is need of installing cleaner burning engines; engines exhaust filters and diesel oxidation catalyst, using special fuels, upgrading ventilation system, providing the equipment cabs with filtered air. These factors can help the workers to prevent lubricant burn smell hazard.

Table. 1 indicates that Mean value for manual lifting object was calculated as 2.45 with S.D of 0.97. A mean value of this variable is near to 2 , therefore, it is considered as 2 . This reveals that respondents of this study were in agreement that this parameter will not affect at all to the performance of workers.

Table. 1 indicates that Mean value of electric shocks was calculated as 1.60 with S.D of 0.87 . The mean value of this variable is near to 2 , therefore, it is considered as 2 . This reveals that 
respondents of this study were in agreement that this parameter will not affect at all to the performance of workers. (OSHA 29 CFR 1910.301-.308) describes requirements for electric shocks that how workers can protect from electrical hazards. The compliance with these regulations makes the workers strong. The cables or wires should be flexible and standard quality. The workers should be trained in accordance with OSHA regulations. Thaker, Phadke, \& Patel, 2013).

Table. 1 indicates that Mean value of this factor was calculated as 1.58 with S.D of 0.70 . The mean value of this variable near to 2 , therefore, it is considered as 2 . This reveals that respondents of this study were in agreement that this parameter is not at all which affect the performance of workers. (OSHA Hazard Bulletin (DSG 06/2014-HB-3731) suggested that personal protective equipment is very essential to protect the workers from accidental fall and overhead falling object hazards. The workers should be trained to use the equipment properly in the workplace.

The accident fall damages the body of workers externally and internally. Most accidents occur due to unbalance and miss-footed at the top of the stairs (Hisao, 2014).

\section{Occupational health and safety practices}

Health is most respected social matter in community and society and playing an important part for successful human efficiency. The productivity of workers can be increased by providing the proper medical facilities paid by industrial organizations. Medical bill facility provides shelter to workers and helps to perform better. The performance and motivation of workers are based on the medical facilities at the workplace. The performance of workers is adversely affected if there is lacking in medical bill paid facilities by the organizations. Hazard awareness means knowledge and information about the potential hazards at the workplace. A hazard is explained as a situation or fluctuating set of surrounding that is available as potential harm, incident, accident and disease (Mohsin, Nebhwani, Soomro, Gopang, \& Ali, 2017).

\section{Table 2}

Occupational health and safety practices

\begin{tabular}{|c|c|c|}
\hline Variable & Mean & SD \\
\hline Medical bill paid by company & 4.53 & 1.037 \\
\hline Awareness of clinic & 4.49 & 1.001 \\
\hline Awareness of hazards & 4.41 & 0.969 \\
\hline Better health make good production & 4.30 & 0.961 \\
\hline Top management attitude with worker & 4.16 & 0.924 \\
\hline Awareness of preventive measure & 4.12 & 1.216 \\
\hline Influenced of mobile on production & 3.91 & 1.249 \\
\hline Using of Inaccurate instrument & 3.91 & 1.063 \\
\hline periodic medical since working & 3.67 & 1.145 \\
\hline Availability of Dust mask & 3.39 & 1.379 \\
\hline Availability of Ear plug & 3.05 & 0.864 \\
\hline pre-employment medical examination & 2.71 & 0.928 \\
\hline Training on hazard prevention & 2.29 & 0.968 \\
\hline Availability of protective devices & 2.28 & 0.798 \\
\hline Availability of Safety boot & 2.26 & 0.758 \\
\hline Availability of Hand gloves & 2.24 & 0.694 \\
\hline Medical bill paid by pocket payment & 2.14 & 0.835 \\
\hline Availability of helmets & 2.13 & 0.619 \\
\hline Availability of Eye goggle & 2.03 & 0.798 \\
\hline
\end{tabular}


Table. 2 shows the results of data collected through questionnaire for the variables of occupational health and safety practices. Statistical results include; Medical bill paid by company $(M=4.53, S D=1.037)$, Awareness of clinic $(M=4.49, S D=1.001)$, awareness of hazards $(M=4.41, S D=0.969)$, impact of better health on production $(M=4.30, S D=0.961)$, attitude of top management with workers $(M=4.16, S D=0.924)$, awareness of preventive measure $(M=4.12, S D=1.216)$, influenced of using mobile on production $(M=3.91, S D=$ 1.249), using of inaccurate instrument $(M=3.91, S D=1.063)$ and periodic medical test since working ( $M=3.67, S D=1.145)$. Mean value of these factors is near to 4 therefore; it is considered as 4 . This means respondents were agreed that these practices were being practiced in their company.

Other variables like availability of dust mask $(M=3.39, S D=1.379)$, availability of earplug $(M=3.05, S D=0.864)$, pre-employment medical examination $(M=2.71, S D=0.928)$. The mean value of these factors is near to 3 therefore; it is considered as 3 . This means respondents disagreed that these practices were being carried out in their company.

While other variable include; training on hazard prevention $(M=2.29, S D=0.968)$, availability of protective devices $(M=2.28, S D=0.798)$, availability of safety boot $(M=2.26, S D=0.758)$, availability of hand gloves $(M=2.24, S D=0.694$, ), medical bill paid by pocket payment $(M=$ $2.14, S D=0.835)$, availability of helmets $(M=2.13, S D=0.619)$ and availability of eye goggle $(M=2.03, S D=0.798)$. The mean value of these two factors is near 2 therefore; it is considered as 2 . The result shows that respondents were strongly disagreed that these safety practice were carried out in their company.

\section{Using personal protective device at workplace}

Personal protective devices are playing a vast role in the occupational health and safety society. Personal protective equipment protects the workers from many diseases at the workplace. Workers feel relaxation and safety by using the protective dress during the manufacturing process. In another word, we can say that it is the backbone of industries. The personal protective equipment protects the workers against safety risk or health at work [68]. Respondents were asked about how often do you use these protective devices include; using of eye goggle, using of helmets, using of the dusk mask, using of the earplug, using of safety boot and using of hand gloves.

\section{Table 3}

Using of personal protective devices at workplace

\begin{tabular}{|l|r|r|}
\hline Variable & \multicolumn{1}{|c|}{ Mean } & SD \\
\hline Using of dust mask & 3.74 & 0.764 \\
\hline Using of ear plug & 1.48 & 0.982 \\
\hline Using of helmet & 1.39 & 0.788 \\
\hline Using of hand gloves & 1.37 & 0.835 \\
\hline Using of eye goggle & 1.28 & 0.804 \\
\hline Using of safety boot & 1.22 & 0.694 \\
\hline
\end{tabular}

Respondents were provided 5 point Likert scale 1 to 5 , whereas, $1=$ not always available, 2 = not necessary, 3 = often forget to use them, $4=$ occasionally use, $5=$ always use. Collected data was statistically analyzed in terms of mean, standard deviation and variance which are reviewed in Table 3. 
Table 3 shows the results of using dust mask $(M=3.74, S D=0.764)$. Mean value for this factor is near to 4 , therefore it is considered as 4 . It means respondents were occasionally using the dust mask in the company. Using of ear plug ( $\mathrm{M}=1.48, \mathrm{SD}=0.928)$, using of helmet $(M=1.39, S D=0.788)$, using of hand gloves $(M=1.37, S D=0.835)$, using of eye goggle $(M=$ $1.28, S D=0.804)$ and using of safety boot $(M=1.22, S D=0.694)$. Analysis shows that mean values of these variables were near to 1 , therefore; it is considered as 1 . It means that respondents were of view that these protective devices were not available in company.

\section{Conclusions}

This research will become more helpful for future research. The study found out the abysmal occupational health and safety practices for workers in textile industries also reduces the workers performance and productivity. Respondents were in great agreement that there was the existence of hazards like; Noise, Fire, Smoking, Fatigue, Drinking alcohol, Job stress, Cotton dust particles and Mainpuri at the great extent and these hazards affect directly or indirectly on the health of workers. Occupational Health and Safety Practices (OHSP) include; Awareness of clinic, Awareness of hazards, better health make good production, workers satisfaction with the attitude of top management, Awareness of preventive measures, influenced of mobile on production, inaccurate instrument make trouble and periodic medical test since working was being carried out in their organizations while; dusk mask, ear plug, preemployment medical examination, training on hazard prevention, availability of protective devices, safety boot and hand gloves were not being carried out in the textile mill. Respondents were also not satisfied with the using of personal protective devices at the workplace.

\section{Recommendations}

This research study recommends the some important points for the textile industry. The maintenance of machines should be compulsory for reducing the noise at the workplace. There is equality between the workers. The safety officer must be compulsory for all industrial organization. No industry should operate without the safety officer in the workplace. It is the responsibilities of government to keep abreast of all changes in the records. All workers should be treated as equal in the eyes of the organization. The industries should provide the adequate and convenient protective dress during the production line. The regular organizational inspections should be organized in order to recognize the hazards and eliminate them from the workplace. The government should take stand on this issue as it will be essential for regulatory departments to see the potentially hazardous industries so as to secure the health of workers. Pre-employment medical examination and Personal protective devices should be compulsory for all workers at the workplace.

\section{Overall Scope of Study}

This study will increase the productivity rate by eliminating the hazardous environment among the workers. In this way, the workers will play a vital role in developing not only the organizational growth but also their professional career while having the safe and healthy environment. The stress, fatigue and monotony will be eliminated and the profit margin of the organization will be increased significantly due to the healthy working environment. The world is going to change and the importance of occupational health and safety has become backbone at working places in the organizations. 


\section{Significance of the Study}

The Scarcity of a sufficient system for the arrangement of Occupational Health and Safety opportunity are conceiving the main weakness in the progressive countries. It is the role of occupational health and safety to promote the extensive health care system for all employees. OHS develops the trade and increases the productivity of manufacturing industries. The occupational accident's impact on the human life. The unsafe working condition decreases the productivity and declines the interest of workers. There are some important factors of OHS that needs to be considered for employee health. The ambition of occupational health and safety cannot be accomplished without the struggle of workers as well as the management. Pakistan and other developing countries are suffering an unstable stage in their economy. World Trade Globalizations is delivering modern challenges in the territory of OHS. War against the enemy with full equipment is equivalent as workforce can fight against hazards with full equipment at the workplace. 
INTERNATIONAL JOURNAL OF ACADEMIC RESEARCH IN BUSINESS AND SOCIAL SCIENCES

Vol. 8, No. 12, Dec, 2018, E-ISSN: 2222-6990 @ 2018 HRMARS

\section{Acknowledgement}

Thanks to Prof. Murlidhar, Mehran University of engineering and technology, Jamshoro and Prof. Song Weiguo, University of science and technology of china, Hefei for supporting me in the research. Thanks to all my friends and students for collection of material and information in the study.

\section{Corresponding Author}

Mohsin Ali Shaikh (Phd Research Scholar)

State Key Laboratory of Fire Science

University of Science and Technology of China, Hefei -230026- Anhui, China

Email: mohsin38@mail.ustc.edu.cn

\section{References}

[1] Bakri, A., Zin, R. M., Minson, M. S., Muhammad, A. (2006, September 6). Occupational Safety and Health Management Systems: Towards Development of Safety and Health Culture. Proceedings of the $6^{\text {th }}$ Asia-Pacific Structural Engineering and Construction Conference (APSEC), Kuala Lumpur, Malaysia. Retrieved June 22, 2017. Available from: http://citeseerx.ist.psu.edu/viewdoc/download?doi=10.1.1.619.7629\&rep=rep1\&type=pdf

[2] Vinodkumar, M. N. (2005). Study of influence of safety engineering and management practices in Selected Industries in Kerala. PhD Thesis. School of Engineering Cochin University of Science and Technology, Kochi. Available from: https://dyuthi.cusat.ac.in/xmlui/bitstream/handle/purl/996/Dyuthi-T0277.pdf?...3

[3] Sheharyar, A. (2016, June 13). Misplaced priority less than $1 \%$ of Sindh budget allocated for environment. Pakistan (PK): the Express Tribune (PK). https://tribune.com.pk/story/1121384/misplaced-priorities-less-1-sindh-budget-allocatedenvironment/.

[4] Malik, N. (2010). Perspective of occupational health and safety in textile industry. PhD Thesis. Department of Rural Sociology. University of Agriculture Faisalabad. Pakistan. http://prr.hec.gov.pk/jspui/bitstream/123456789/655/1/614S.pdf

[5] Rana, I. M. (2005). Work places in industries, The daily Dawn (pp.18)

[6] Farooqui, R. U., Ahmed, S. M., \& Panthi, K. (2007, July 11-13). Developing safety culture in Pakistan construction industry - An assessment of perceptions and practices among construction contractors. Proceedings of the Fourth International Conference on Construction in the $21^{\text {st }}$ Century: Accelerating Innovation in Engineering, Management and Technology (CITC IV 2007), Gold Coast (Australia), 420-437.

[7] Waqas, A. Khan., Talha, M., \& Tabassum, A. (2014). Occupational Health Safety and Risk Analysis. International Journal of Science, Environment, 3(4), 1336 - 1346.

[8] Hassan, S. A. (2012). Health, safety and environmental practices in the construction sector of Pakistan, Department of Earth Sciences Master thesis. Uppsala University, Department of Earth Sciences. Available at: http://www.diva-portal.org/smash/get/diva2:562426/FULLTEXT01.pdf.

[9] Jaiswal, A. (2012). A case control study among carpet thread factory workers in Uttar Pradesh. Global Journal of Human Social Science, 12(1), 23-30.

[10] Aderaw, Z., Dagnew, E., \& Tadesse, T. (2011). A Case Control Study among Textile Factory Workers in Amhara Regional State Ethiopia. Journal of Tropical Medicine, 2011(2), 1-9. 
INTERNATIONAL JOURNAL OF ACADEMIC RESEARCH IN BUSINESS AND SOCIAL SCIENCES

Vol. 8, No. 12, Dec, 2018, E-ISSN: 2222-6990 @ 2018 HRMARS

[11] Illmarinen, J. (1997). Aging and work-coping with strengths and weaknesses. Scandinavian Journal of Work Environment and Health, 23 (1), 3-5.

[12] Larkin, L., Strong, M. P. H., Frederick, J., \& Zimmerman, Z. (2005). Occupational injury and absence from work among African American, Hispanic, and non-Hispanic white workers in the national longitudinal survey of youth. American Journal Public Health, 95 (7), 1226-1232.

[13] Ahn, Y. S., Bena, J. F., \& Bailer, A. J. (2004). Comparison of Unintentional fatal Occupational Injuries in the Republic of Korea and the United States. Injury Prevention, 10, 199-205.

[14] Gupta, G., Nag, S., Datta, D., Roy, S., Das, S., \& Yasir, S. M. (2015). Occupational health hazards among workers in garment factories in Bangladesh: A Cross-Sectional Study. Journal of Natural Science Research, 5 (5), 90-98.

[15] Hiremath, B., Kuttumuri, R., Kumar, B., \& Hiremath, G. R. (2014). Health and safety aspects of textile workers from Solapur textile industries. Indian Journal of Community Health, 26, 1-7.

[16] Mukremin, E. R., Emri, S. A., Demir, A. U., Thorne, P., Karakoca, Y., Bilir, N., \& Baris, I. (2016). Byssinosis and COPD rates among factory workers manufacturing hemp and jute. International Journal of Occupational Medicine and Environmental Health, 29, 55-68.

[17] Narayanan, A., Mathew, C., \& Vinodyeldo, B. (2013). Improvement of ergonomic factors that affects employees in a textile industry. International Journal of Engineering Science and Innovative Technology, 2, 276-283.

[18] Ofoegbu, O. E., Olawepo, G. T., \& Ibojo, B. O. (2013). Effects of occupational hazards on employees' productivity. European Journal of Business and Management, 5, 1905- 2222.

[19] Musa, O., \& Bamidele, J. (2012). Occupational hazards awareness and safety among cement factory workers at Obajanakogi State Nigeria. Elixir International Journal Bio Diversity, 47, 90139018.

[20] Draugalis, J. R., Coons, S. J., \& Plaza, C. M. (2000). Best practices for survey research reports: a synopsis for authors and reviewers. The American Journal Pharmaceutical Education, 72 (1), 1-6.

[21] Skeers, J., (2006). 54 workers killed in textile factory fire. Bangladesh, https://www.wsws.org/en/articles/2006/03/bang-m02.html.

[22] Halpern, T., Shikiar, R., Rentz, M., \& Zeba, M. K. (2011). Impact of smoking status on workplace absenteeism and productivity. Tobacco Control, 10 (3), 233-238.

[23] Procopio, F., Cruz, P., Scavonec, M., Giunta, L., Pestana, O., and Roza, A. (2014). Fatigue effects in daily life activities of kidney transplant recipients. Transplantation Proceeding, 46 (6) 1745-1749.

[24] Breslow, M. J. (1992). The role of stress hormones in perioperative myocardial ischemia. International Anesthesiology Clinic, 30 (1), 81-100.

[25] Gmel, G., \& Rehm, J. (2003). Harmful alcohol use. Alcohol Research \& Health, 27 (1), 52-62.

[26] Li, C. Y., Chen, K. R., Wu, C. H., \& Sung, F. C. (2001). Job Stress and Dissatisfaction in Association with Non-Fatal Injuries on the Job in a Cross-Sectional Sample of Petrochemical Workers. Occupational Medicine, 51 (1), 50-55.

[27] Kane, C. D. (2001). Environmental and Health Hazards in Spinning Industry and their Control. Indian Journal of Fibre \& Textile Research, 26 (1), 39-43.

[28] Haider, D., Taous, A., Rahim, M., Zahurul Huq, A., \& Abdullah, M. (2008). Noise induced hearing loss among the textile industry workers. Bangladesh Journal of Otorhinolaryngology, 14 (2), 3945. 
INTERNATIONAL JOURNAL OF ACADEMIC RESEARCH IN BUSINESS AND SOCIAL SCIENCES

Vol. 8, No. 12, Dec, 2018, E-ISSN: 2222-6990 C 2018 HRMARS

[29] Newspapers staff reported. (2011, December 29), Harmful gutka, mainpuri banned, Karachi Pakistan: the dawn news. Available from: https://www.dawn.com/news/684066.

[30] Serkalem, Y. S., Haimanot, G. M., \& Ansha N. (2014). The determination of occupational injury in Kombolcha textile factory North-East Ethiopia. The International Journal of Occupational and Environmental medicine, 5(2), 84-93.

[31] Amina, H., \& Shehla, A. (2009). Impact of office design on employee's productivity: A Case study of Banking. Journal of Public Affairs Administration and Management, 3 (9), 1-8.

[32] Seppanen, O., William, J. F., Lie, Q. H. (2006). Effect of temperature on task performance in office environment. Proceeding on the $5^{\text {th }}$ international Conference on Cold Climate Heating, Ventilating and Air Conditioning, Russia Moscow, Pagination.

[33] Farhan, S. (2010). Naswar more injurious to health than smoking. The express tribune. Available from: https://tribune.com.pk/story/80477/naswar-more-injurious-to-health-than-smoking/.

[34] Ind, J. E., \& Jeffries, D. J. (1999). Needle sticks injury in clothing industry workers and the risks of blood-borne infection. Occupational Medical Journal, 49, 47-49.

[35] Thaker, M., Phadke, B., \& Patel, P. (2013). Effects of electrical hazards. International Journal of Emerging Technology and Advanced Engineering, 3 (9), 569-574.

[36] Hisao, N. (2014). Case study on possible falling patterns of a fatal fall from stairs. Journal of Industrial Health, 52, 432-438

[37] Mohsin, A. S., Nebhwani, M., Soomro, S., Gopang, M., Ali, S. (2017, Febuary 20-22). Impact of Medical Facilities Provided by Industrial Organization on Productivity, International Conference on Industrial Engineering and Management Applications (IEMA), Mehran University of engineering and technology, Jamshoro, ISBN\# 978-969-7710-01-0. http://iema.muet.edu.pk/. 